\title{
Increase in Accuracy of a Built-in Spindle by Adaptive Cooling Control with Varied Coolant Volume and Temperature
}

\author{
Kun-Ying Li, ${ }^{1}$ Win-Jet Luo, ${ }^{1 *}$ Yu-Ru Zeng, ${ }^{2}$ and I-Hsing Huang ${ }^{2}$ \\ ${ }^{1}$ Graduate Institute of Precision Manufacturing, National Chin-Yi University of Technology, \\ No. 57, Sec. 2, Zhongshan Rd., Taiping Dist., Taichung 41170, Taiwan \\ ${ }^{2}$ Department of Refrigeration, Air-Conditioning and Energy Engineering, National Chin-Yi University of \\ Technology, No. 57, Sec. 2, Zhongshan Rd., Taiping Dist., Taichung 41170, Taiwan
}

(Received June 25, 2020; accepted October 22, 2020)

Keywords: spindle, thermal deformation, steady state, regression model

Machine tools are an indispensable part of the modern manufacturing industry, by which many items are produced. In the manufacturing process, machining accuracy is very important for the precision of products. However, the thermal error accounts for $40-70 \%$ of the machining error. Most of the machine tool heat created during machining originates from the rotating spindle owing to the internal bearing friction and motor power loss. Cooling systems are designed to remove the heat generated in the spindle in real time by coolant circulation to maintain the spindle temperature and improve the machining accuracy of the machine tool. In this study, the thermal deformation of a spindle was investigated under different rotating spindle speeds. To adapt to cooling demand variations at different rotating speeds, the cooling capacity of the cooling system was controlled by changing the supply volume and supply temperature of the coolant to the spindle. The effects of supply coolant volume, supply coolant temperature, and ambient temperature on the thermal deformation of the spindle were analyzed. A regression model for the driving frequency of the coolant pump in terms of the spindle rotational speed and coolant temperature difference was developed. By changing the supply coolant volume and coolant temperature difference in accordance with the spindle rotating speed, the accuracy of the deformation was reduced by up to $25 \%$, and the required time to attain a steady state was also shortened. The shortest required time of $12 \mathrm{~min}$ was attained with a pump driving frequency of $80 \mathrm{~Hz}$ and a coolant temperature difference of $4{ }^{\circ} \mathrm{C}$ at a spindle rotating speed of $24000 \mathrm{rpm}$. The developed regression model was verified in three dynamical operational processes with different periods in which the spindle rotating speed was changed.

\section{Introduction}

Thermal deformation accounts for 40 to $70 \%$ of the machining error of machine tools. The thermal error of a machine is mainly caused by the heat generated during operation, which

*Corresponding author: e-mail: wjluo@ncut.edu.tw https://doi.org/10.18494/SAM.2020.3104 
can be divided into external and internal heat sources. Usually, ambient temperature control is used to remove or stabilize external heat sources. ${ }^{(1)}$ However, for internal heat sources, the heat generation is unstable and complicated, and thermal errors of the machine tool structure are difficult to control. Past studies often used thermal compensation and thermal suppression to improve thermal accuracy regarding internal heat sources. However, the accuracy of the thermal compensation method usually depends on the accuracy of the thermal error model and the ambient temperature stability. ${ }^{(2)}$ Changes in ambient temperature may reduce the thermal accuracy of the thermal compensation model.

In general, most precision machine tools adopt cooling systems to remove the heat generated in the spindle, ball screw, and feed system during machining to maintain high manufacturing precision. $^{(3-5)}$ Owing to their mechanical structure design, thermal isolation ${ }^{(6,7)}$ or thermal balance design ${ }^{(8)}$ is considered to reduce the thermal errors of machine tools in operation.

In recent years, with the advancement of simulation analysis software, some studies have adopted simulation methods to analyze the cooling channel efficiency of the spindle. Wu et al. ${ }^{(9)}$ performed simulation analysis to establish a thermal model for a high-rotational-speed spindle in a machine tool and analyzed the steady-state thermal performance of the spindle under different machining feed rates. From the analysis results, the cooling channel design was modified, and the structural temperature of the spindle decreased significantly. Moorthy et al. ${ }^{(10)}$ analyzed the flow and temperature distributions in a built-in spindle with a dual-spiral cooling channel. The temperature distribution of the high-speed spindle structure with a maximum rotating speed of $40000 \mathrm{rpm}$ was analyzed. The effect of heat flux under different cooling water flow rates was investigated. The results showed that the cooling efficiency of a dual-spiral channel is better than that of a single-spiral channel. Weber et al $^{(11)}$ performed the computational fluid dynamics (CFD) simulation analysis of different cooling channel designs for a built-in spindle and discussed the effect of the surface roughness of the cooling channel on the heat convection coefficient. It was found that the heat transfer coefficient was increased by increasing the surface roughness. Li et al. ${ }^{(12,13)}$ performed multiphysics simulation analysis on the cooling channel design of a built-in spindle. The design of experiments (DOE) method was employed to optimize the dimensions of the cooling channel, and practical machining experiments were performed to validate the thermal performance of the design. By optimizing the design of the cooling channel, the bearing temperature was reduced by up to $6.7^{\circ} \mathrm{C}$ and the spindle deformation was also reduced from 53.8 to $30.9 \mu \mathrm{m}$.

The spindle is one of the most important components of CNC machine tools. In machining plants, the accuracy and thermal suppression of the spindle strongly affect the accuracy and quality reliability of machining parts. ${ }^{(14)}$ Chiang et al. ${ }^{(15)}$ proposed a novel proportional-integral-derivative (PID) control logic based on the Smith prediction method to control the coolant outlet temperature by MATLAB simulation. The simulation results showed that the proposed control scheme has a higher temperature control accuracy than the traditional PID control scheme, and the steady-state error of the supply coolant temperature was controlled within $0.1^{\circ} \mathrm{C}$. Li et al. ${ }^{(16)}$ developed a control method based on the variation in coolant volume for the dynamical machining of a spindle. Under changes in the machining 
load of the spindle, different coolant volumes can be supplied to the spindle to improve the machining accuracy of workpieces. Huang et al. ${ }^{(17)}$ investigated the temperature increase of the cooling channel and the thermal deformation of a built-in spindle by experiments and simulations. A simulation model was used to analyze the effect of the cooling channel. The results showed that the cooling efficiency of the reciprocating channel type is higher than that of the spiral channel type. Grama and Badhe ${ }^{(18)}$ proposed the cooler trigger model (CTM), which can significantly improve the cooling efficiency. By controlling the operational on-off frequency of a cooler in accordance with the cooling load variation, the heat generated in the spindle can be extracted dynamically, and a steady state inside the spindle can be attained. A comparison was made between the ambient temperature tracing strategy (ATS) and the CTM cooling strategy in ambient temperature variation error (ETVE) control. For a wide range of spindle speeds, the CTM strategy is advantageous for motor and bearing temperature stability, and it can significantly reduce thermal errors. Mori et al. ${ }^{(19)}$ controlled the on-off operation of a cooling system compressor in terms of the equilibrium relationship between the heat transfer rate and the thermal deformation to minimize the thermal deformation of a machine tool, and experiments were conducted to verify the improved cooling efficiency of the proposed method.

Regarding the thermal suppression methods used in previous studies and applications, a constant coolant volume and a constant coolant temperature are usually supplied from the cooling system, which generally cannot provide a real-time response to varying cooling demand under different machining loads. Therefore, the accuracy of the machine tool cannot be further improved by the design. The rate of heat removal by the coolant is proportional to the coolant flow rate and the temperature difference between the coolant at the inlet and that at the outlet of the cooling channel in the spindle. More heat can be removed by coolant flow with a higher flow rate and a lower temperature of the supplied coolant at the inlet. However, a constant inlet coolant temperature and a constant flow rate may lead to either the excessive or insufficient cooling of the spindle. An excessive supply of coolant may result in the shrinkage deformation of the spindle due to overcooling. Conversely, an insufficient coolant flow rate may lead to the deformation of the spindle due to thermal expansion and require a longer warm-up time to attain the thermal steady state of the spindle. Thus, effectively controlling the supply coolant volume and coolant temperature in accordance with the cooling load of the spindle is essential for reducing thermal deformation and enhancing the machining accuracy of the spindle.

The utilization of the variable coolant volume and coolant temperature (VOV/T) method to adapt to variations in dynamical cooling demand in real time and further increase the spindle accuracy has never been proposed or investigated in the literature. In this study, the effect of the proposed VOV/T method on the thermal deformation of a spindle under different rotating speeds was investigated to establish a coolant supply model for the spindle. The effect of the developed coolant supply model on the thermal deformation of the spindle in dynamic operations was validated with different periods in which the rotating speed of the spindle was changed. Moreover, the VOV/T method was also applied to shorten the required warm-up time of the spindle. 


\section{Experimental Setup and Thermal Deformation Measurement}

\subsection{Experimental setup}

In this study, the built-in spindle of a machine tool (213A370, Setco) was adopted, as shown in Fig. 1. The maximum rotating speed of the spindle was $24000 \mathrm{rpm}$. The spindle motor had a torque of $6 \mathrm{~N}-\mathrm{m}$ and a rated horsepower of $7.5 \mathrm{~kW}$. Figure 1(a) shows the configuration and dimensions of the built-in spindle, which consisted of a rear bearing, a built-in motor, and a front bearing. Figure 1(b) shows the setup of the experimental equipment, which consisted of a spindle, a test bar, and measurement devices. Figure 1(c) shows the thermal deformation measurement of the spindle based on the ISO 230-3 specification. ${ }^{(20)}$ A test bar was clamped on the spindle, and eddy current sensors (AEC S-06) were used to measure thermal deformations. When the spindle operated, the displacements of the spindle in the $X$-, $Y$-, and $Z$-directions were obtained using the measuring devices.

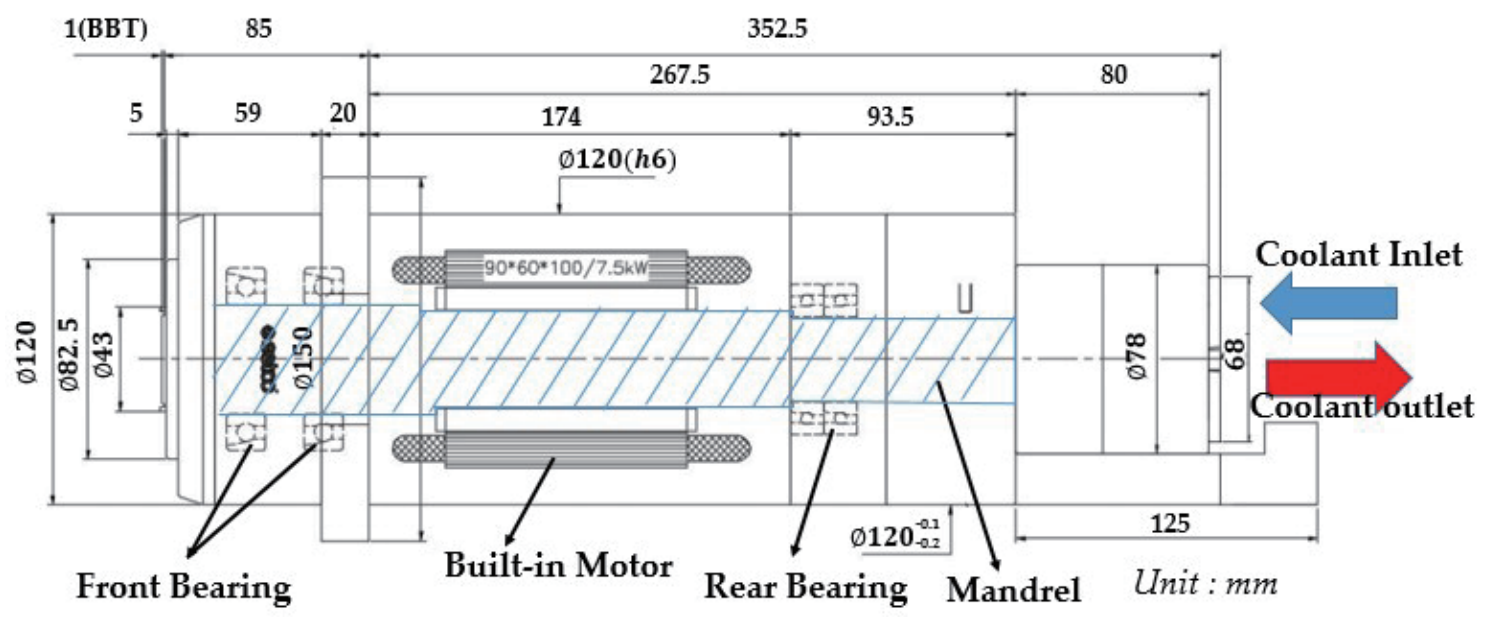

(a)

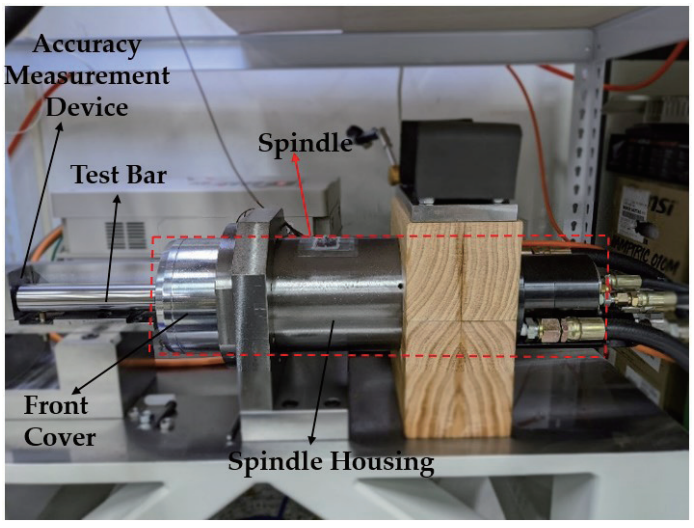

(b)

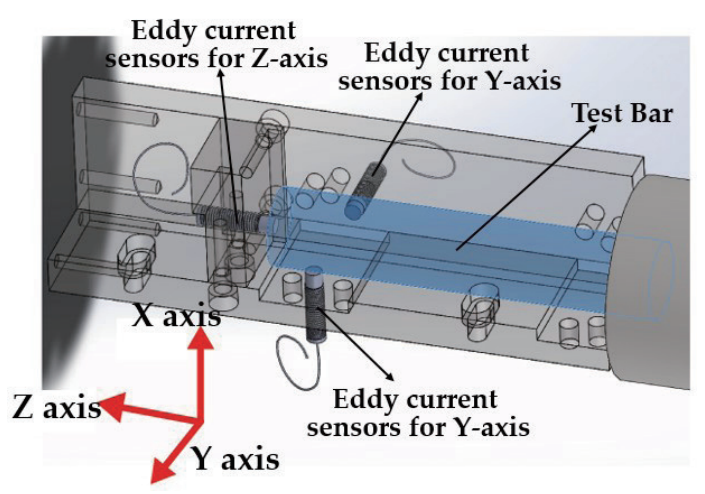

(c)

Fig. 1. (Color online) Experimental setup: (a) dimensions of built-in spindle; (b) experimental setup; and (c) measurement devices in test bar. 
Uncertainties in measuring any physical quantity are always present owing to instrumental, physical, and human imperfections. ${ }^{(21)}$ Uncertainty analysis is the procedure employed to assess the uncertainty from measured variables with known uncertainties. In this study, the experimental influencing factors and corresponding uncertainties include the following: (1) an ambient temperature variation of $\pm 1{ }^{\circ} \mathrm{C}$; (2) a temperature sensor (Trump NCP02 thermistor) accuracy of $-40-125{ }^{\circ} \mathrm{C} \pm 0.01 \%$; (3) a cooling oil flowmeter (NEW FLOW, DPG 3000) error of $\pm 0.5 \%$; (4) a signal-measuring instrument (GL840M) error of $\pm 0.002 \%$; (5) an eddy current sensor (AEC-S06) error of $\pm 1 \%$. According to Kline and McClintock, ${ }^{(21)}$ the total measurement uncertainty is $\pm 4.15 \%$ in this study. The overall uncertainty was calculated as the root of the sum of the square of each uncertainty using the equation $\Delta y=\left[\left(\Delta x_{1}\right)^{2}+\left(\Delta x_{2}\right)^{2}+\ldots+\left(\Delta x_{n}\right)^{2}\right]^{1 / 2}$, where $\Delta x_{1}, \Delta x_{2}, \ldots, \Delta x_{n}$ are the uncertainties of the individual variables.

\subsection{Spindle cooling system}

In this study, a self-made cooling system with a coolant pump was adopted to supply coolant to the spindle for heat exchange. Figure 2 illustrates the system developed for spindle cooling. The system consists of two circulation loops: the coolant and refrigerant loops. The left loop is the coolant loop, which is mainly composed of the spindle, a coolant storage tank, and a coolant pump. The right loop is the refrigeration loop, which consists of a compressor, a condenser, an expansion valve, and a plate heat exchanger. In the refrigerant cycle, the liquid refrigerant driven by the compressor absorbs heat from the circulating coolant in the plate heat exchanger, evaporates into a gas, and then returns to the compressor. The gas refrigerant is compressed at a high pressure and then it condenses into a liquid, which dissipates the condensation heat to the ambient through the condenser. The pressure of the liquid refrigerant after the condenser is reduced by passing it through an expansion valve, after which the refrigerant returns to the plate heat exchanger to complete the cycle. The temperature of the circulating coolant is reduced in the plate heat exchanger, and the low-temperature coolant is pumped to the rotating spindle to remove the heat generated in the operational process.

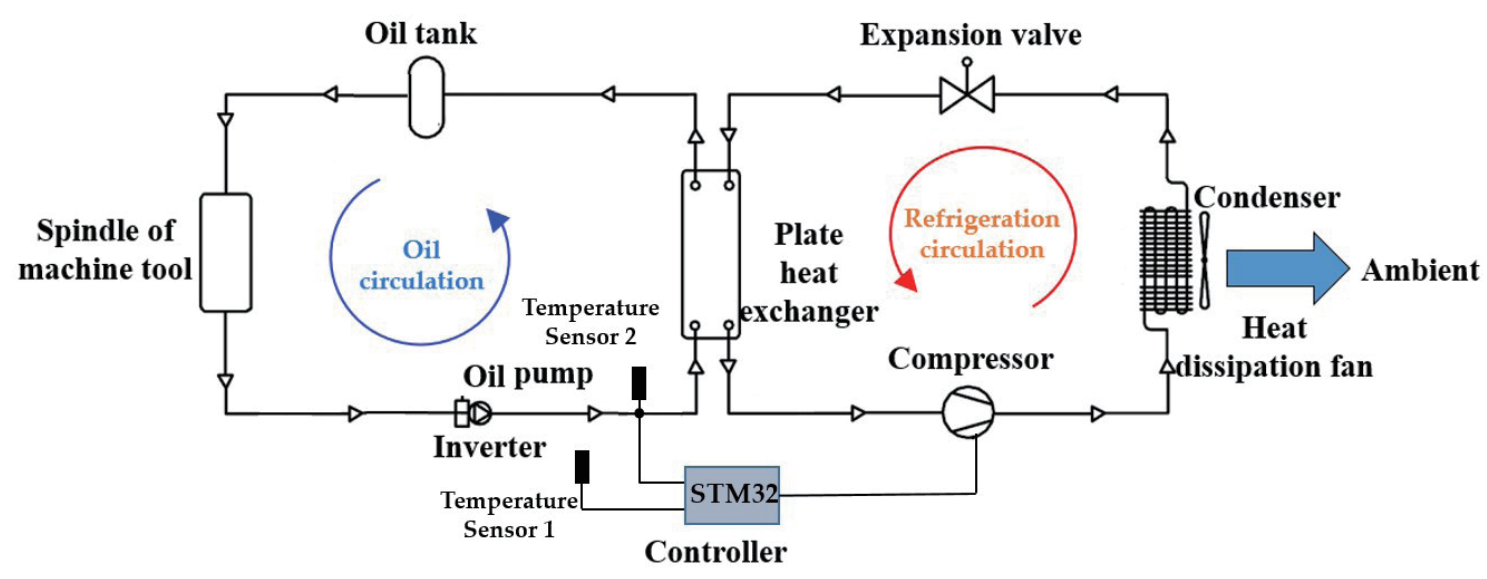

Fig. 2. (Color online) Cooling control system. ${ }^{(12,13)}$ 
In this study, the ambient temperature was treated as the reference temperature for the return coolant. The coolant temperature sensor at the inlet of the plate heat exchanger instantly responds to the inverter of the compressor to adjust the refrigerant flow rate in the refrigeration cycle in accordance with the cooling load variation of the spindle. The temperature difference between the ambient and the coolant that returns from the spindle is controlled using an STM32 PID controller. The refrigerant flow rate in the refrigeration cycle is controlled using a variable-speed compressor. The signals of the ambient and coolant temperatures are sent to the STM32 PID controller, and then the PID controller outputs a relative voltage signal to control the compressor driving frequency and coolant supply temperature.

\subsection{Heat source measurement and calculation}

In the experiments, the required power of an operational spindle motor was measured using a HIOKI PW3360 power meter. ${ }^{(22)}$ Figure 3 shows a flow chart of the spindle power measurement. The built-in spindle motor adopted for the spindle was a three-phase motor with a voltage of $380 \mathrm{~V}$. After the driver of the spindle was initiated, the rotating speed of the spindle was controlled by adjusting the frequency of the inverter. In the dynamic operation of the motor, the current, voltage and power factor of the spindle were extracted using the current digital clamp of the power meter. The measured information was sent to a computer through a USB communication interface for data analysis and then compared with theoretical values.

\subsection{Theory of thermal deformation}

The thermal deformation of materials can be calculated using Hooke's law. ${ }^{(23)}$ By using the principle of superposition, the deformation due to stress and temperature effects can be obtained. As shown in Fig. 4, when the temperature increases by $\Delta T$, the elongation in all

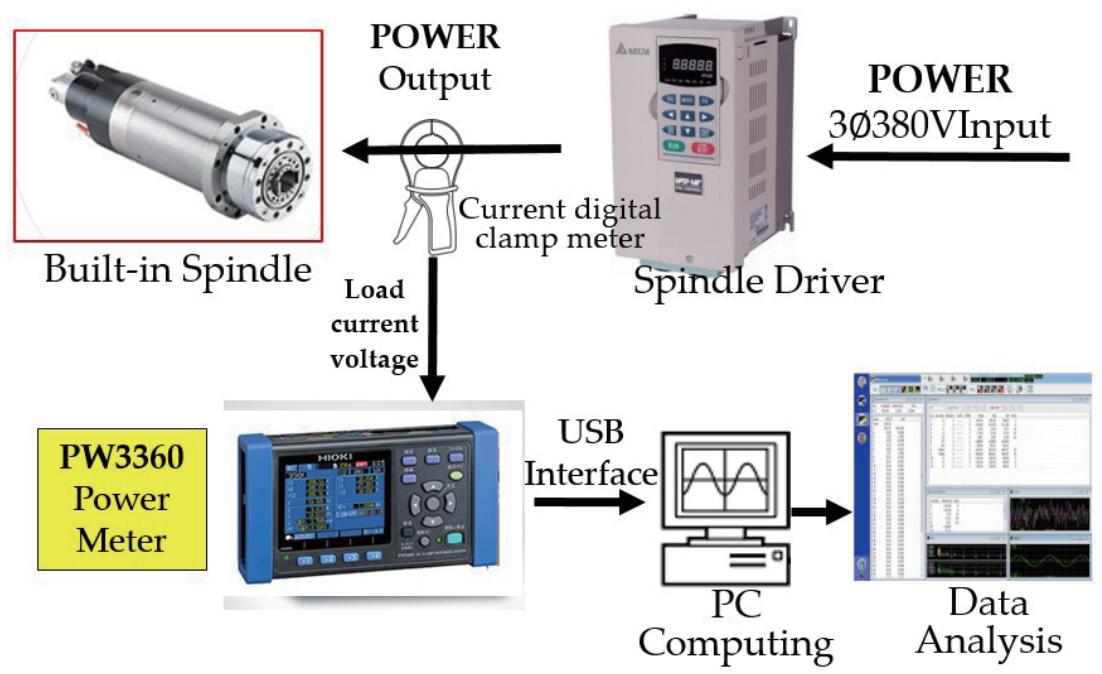

Fig. 3. (Color online) Spindle power measurement process. 


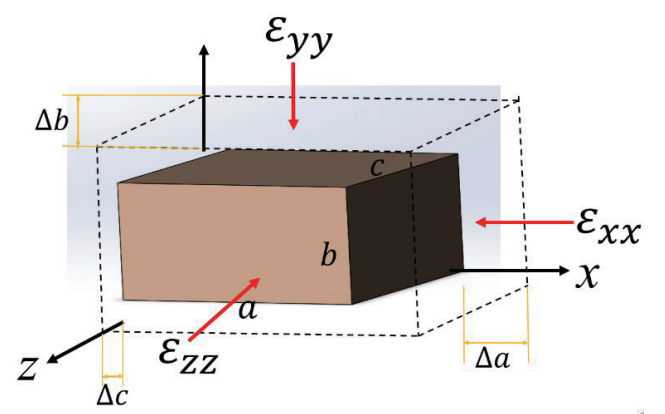

Fig. 4. (Color online) Schematic diagram of thermal deformation. ${ }^{(15)}$

directions can be obtained. When the stress and temperature effects are applied at the same time, the strains in all directions can be obtained using the principle of superposition, where $\varepsilon_{x x}$ is the strain in the $x$-direction, $\varepsilon_{y y}$ is the strain in the $y$-direction, and $\varepsilon_{z z}$ is the strain in the $z$-direction. Therefore, when the stress and temperature effects are applied simultaneously, the strains in all directions can be obtained using the overlapping principle as

$$
\begin{gathered}
\varepsilon_{x x}=\frac{\sigma_{x x}-v\left(\sigma_{y y}+\sigma_{z z}\right)}{E}+\alpha \cdot \Delta T, \\
\varepsilon_{y y}=\frac{\sigma_{y y}-v\left(\sigma_{x x}+\sigma_{z z}\right)}{E}+\alpha \cdot \Delta T, \\
\varepsilon_{z z}=\frac{\sigma_{z z}-v\left(\sigma_{x x}+\sigma_{y y}\right)}{E}+\alpha \cdot \Delta T,
\end{gathered}
$$

where $E$ is Young's modulus, $v$ is Poisson's ratio, and $\sigma$ is the stress. $\sigma$ can be obtained from $\sigma=E_{\varepsilon} . \alpha$ is the coefficient of thermal expansion and $\Delta T$ is the temperature difference.

\subsection{Regression analysis}

Regression analysis is a statistical analysis method used to determine whether two or more variables are related and to build mathematical models to observe and predict specific variables. Regression analysis can be divided into simple and multiple regressions. Simple regression is used to explore the relationship between one dependent variable and one independent variable. Multiple regression is an analytical method that uses two or more independent variables in the regression equation. ${ }^{(24)}$

In this study, the coolant volume in the cooling system was evaluated on the basis of the spindle speed and coolant temperature difference. Therefore, for different cooling requirements of the spindle, multiple regression was used to obtain a suitable spindle coolant volume. This multiple regression can be expressed as 


$$
y_{t}=\beta_{0}+\beta_{1} x_{1 t}+\beta_{2} x_{2 t}+\ldots+\beta_{n} x_{n t}+\varepsilon_{t},
$$

where $y_{t}$ is a dependent variable, $x_{1 t}, \ldots, x_{n t}$ are independent variables, $\beta_{0}$ is a constant, $\beta_{1}, \ldots, \beta_{n}$ are regression coefficients, and $\varepsilon_{t}$ is the error.

\section{Coefficient of multiple determination:}

The coefficient of multiple determination is used to indicate the goodness of fit of the regression model and is defined as

$$
R^{2}=\frac{S S R}{S S T}=1-\frac{S S E}{S S T}
$$

where $S S R$ is the regression sum of squares, $S S T$ is the sum of squares, and SSE is the residual sum of squares. $R^{2}\left(0 \leq R^{2} \leq 1\right)$ indicates the strength of the relationship between the dependent and independent variables. High $R^{2}$ values indicate that the dependent variables can be well predicted from the independent variables using the regression equation.

\section{Results and Discussion}

The spindle speed was controlled using a motor driver (VFD-VE series, Delta). The rotating speed of the spindle was proportional to the driving frequency of the spindle motor. When the rotating speed of the spindle was less than a specific value, the operational voltage of the spindle increased linearly with the driving frequency. After the rotating speed reached a specific value, the operational voltage of the spindle was almost constant and the operational current of the spindle decreased significantly, as shown in Fig. 5. The operational voltage increased with the operational speed of the spindle when the speed was below $17000 \mathrm{rpm}$. When the speed

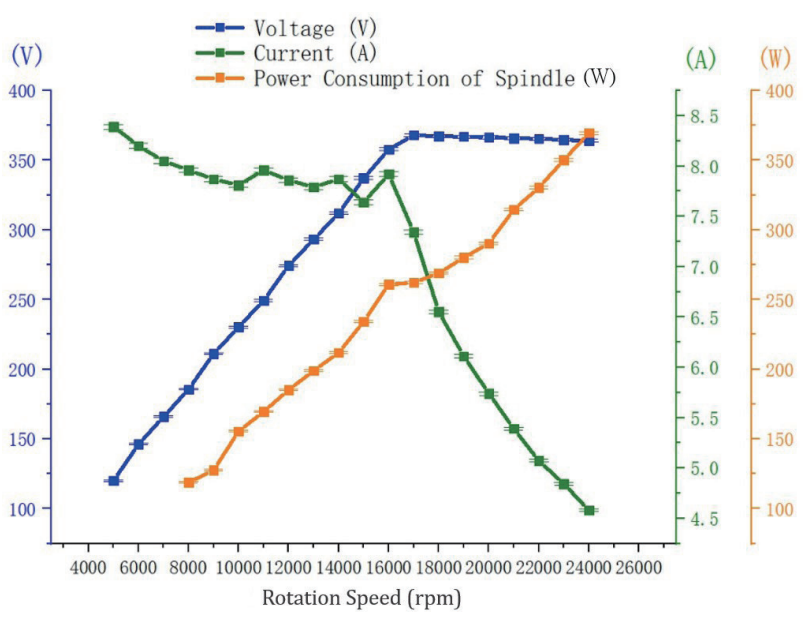

Fig. 5. (Color online) Operational voltage, current, and power consumption of spindle under different operational speeds. 
was greater than $17000 \mathrm{rpm}$, the highest operational voltage of the spindle remained at or near $367 \mathrm{~V}$ and the current dropped significantly. The heat generated by the spindle varied with the operational speed. The power consumption of the spindle motor was measured using a power meter and found to be $118 \mathrm{~W}$ at the operational speed of $8000 \mathrm{rpm}$. As the operational speed of the spindle gradually increased to $24000 \mathrm{rpm}$, the power consumption increased to $369 \mathrm{~W}$.

The effects of the coolant supply volume and temperature from the cooling system on the thermal deformation under different spindle rotating speeds were investigated in this study. The volume and temperature of the coolant supplied from the cooling system were controlled by adjusting the driving frequencies of the coolant pump and refrigerant compressor, respectively. The spindle rotating speed was increased from 8000 to $24000 \mathrm{rpm}$ at intervals of $4000 \mathrm{rpm}$. At each spindle rotating speed, the coolant driving frequency was adjusted to 40,60 , and $80 \mathrm{~Hz}$, and the difference between the temperature of the coolant detected using temperature sensor 2 and the ambient temperature detected using temperature sensor 1 was controlled at $0,-2$, and $-4{ }^{\circ} \mathrm{C}$ by adjusting the rotating speed of the compressor. The general cooling conditions were a constant supply coolant volume and a constant temperature difference (COV/T), a driving frequency of $60 \mathrm{~Hz}$, and a temperature difference of $0{ }^{\circ} \mathrm{C}$. Currently, the COV/T method is often used in the applications of machine tool spindle cooling. The COV/T method cannot apply real-time response to the required cooling condition under different machining loads. Therefore, the cooling method of COV/T causes poor cooling efficiency of the spindle and produces accuracy errors. To compare the efficiency of the cooling method in this study with that of the general cooling method $(\mathrm{COV} / \mathrm{T})$ and model a general cooling system, the COV/T from the cooling system were designed at a driving frequency of $60 \mathrm{~Hz}$ and a temperature difference of $0{ }^{\circ} \mathrm{C}$.

From Fig. 6, it can be seen that the thermal deformation in all directions was affected by the coolant driving frequency and coolant temperature difference at a given spindle rotating speed. Figure 6(a) illustrates the thermal deformation of the spindle in the $X$-direction at $8000 \mathrm{rpm}$ under different coolant supply conditions. The maximum thermal deformation in the $X$-direction was $8.27 \mu \mathrm{m}$ with a coolant driving frequency of $60 \mathrm{~Hz}$ and a coolant temperature difference of $4{ }^{\circ} \mathrm{C}$. The minimum thermal deformation in the $X$-direction was $0.13 \mu \mathrm{m}$ with a coolant driving frequency of $80 \mathrm{~Hz}$ and a coolant temperature difference of $4^{\circ} \mathrm{C}$. Under the general cooling control (COV/T) method with a coolant driving frequency of $60 \mathrm{~Hz}$ and a coolant temperature difference of $0{ }^{\circ} \mathrm{C}$, the thermal deformation was $-0.54 \mu \mathrm{m}$, which was larger than that for a coolant driving frequency of $80 \mathrm{~Hz}$ and a coolant temperature difference of $4{ }^{\circ} \mathrm{C}$. By comparing the best cooling conditions (a coolant driving frequency of $80 \mathrm{~Hz}$ and a coolant temperature difference of $\left.4^{\circ} \mathrm{C}\right)$ with general cooling conditions (COV/T, a driving frequency of $60 \mathrm{~Hz}$, and a coolant temperature difference of $0{ }^{\circ} \mathrm{C}$ ), the thermal deformation in the $X$-direction was observed to decrease to $0.41 \mu \mathrm{m}$.

Figure 6(b) illustrates the thermal deformations of the spindle in the $Y$-direction at $8000 \mathrm{rpm}$ under different coolant conditions. From the results, the maximum thermal deformation in the $Y$-direction was $7.77 \mu \mathrm{m}$ with a coolant driving frequency of $40 \mathrm{~Hz}$ and a coolant temperature difference of $2{ }^{\circ} \mathrm{C}$. The minimum thermal deformation in the $Y$-direction was $0.42 \mu \mathrm{m}$, which occurred at a coolant driving frequency of $40 \mathrm{~Hz}$ and a coolant temperature difference of $0{ }^{\circ} \mathrm{C}$. 


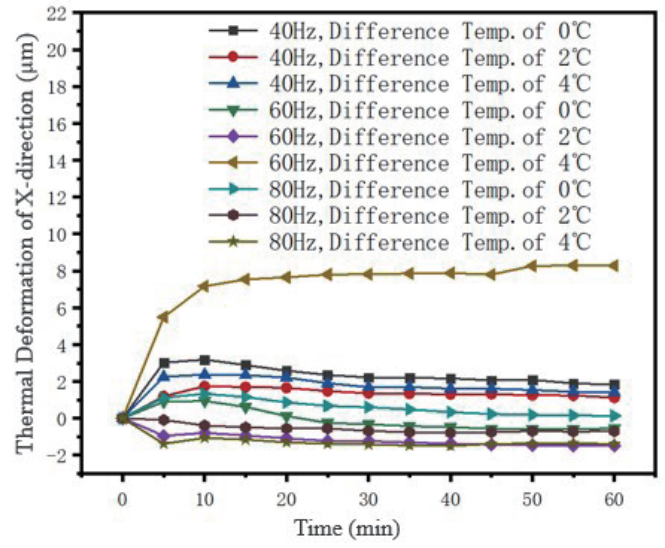

(a)

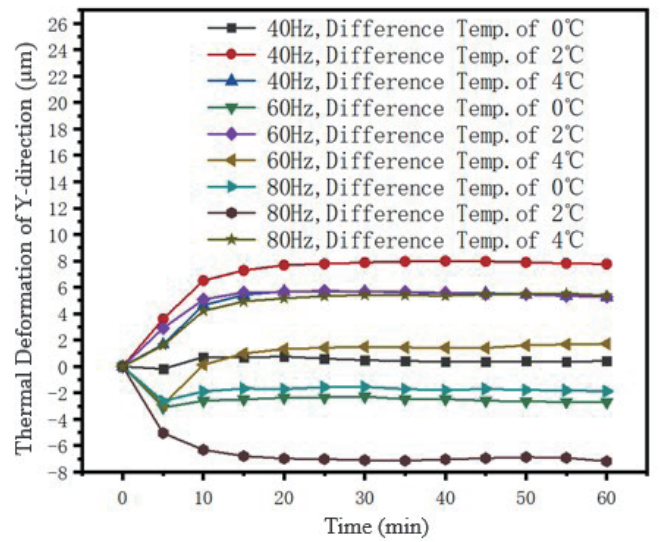

(b)

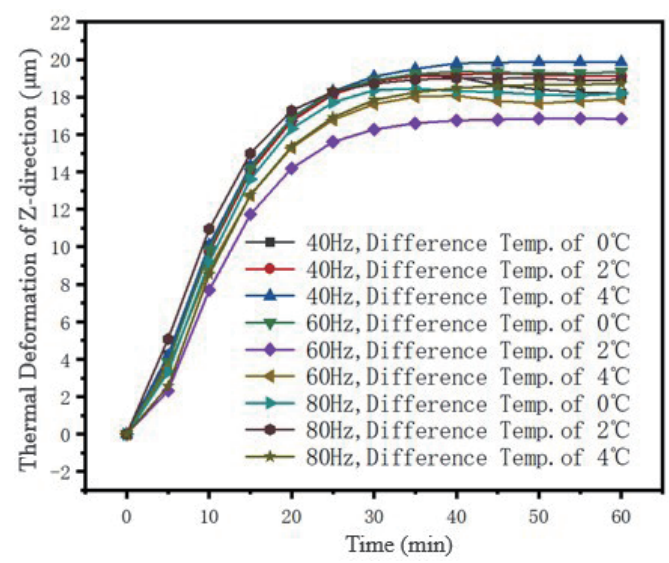

(c)

Fig. 6. (Color online) Thermal deformations of the spindle at $8000 \mathrm{rpm}$ under different cooling oil conditions: (a) $X$-direction, (b) $Y$-direction, and (c) Z-direction.

In comparison with the COV/T cooling method with a driving frequency of $60 \mathrm{~Hz}$ and a coolant temperature difference of $0{ }^{\circ} \mathrm{C}$, the thermal deformation was $-2.70 \mu \mathrm{m}$. By comparing the best cooling conditions (a coolant driving frequency of $40 \mathrm{~Hz}$ and a coolant temperature difference of $0^{\circ} \mathrm{C}$ ) with general cooling conditions, the thermal deformation in the $Y$-direction was found to decrease to $2.28 \mu \mathrm{m}$. Figure 6(c) illustrates the thermal deformations of the spindle in the $Z$-direction at $8000 \mathrm{rpm}$ under different coolant conditions. From the results, the maximum thermal deformation in the $Z$-direction was determined to be $19.87 \mu \mathrm{m}$, which occurred at a coolant driving frequency of $40 \mathrm{~Hz}$ and a coolant temperature difference of $4{ }^{\circ} \mathrm{C}$. The minimum thermal deformation in the $Z$-direction was $16.83 \mu \mathrm{m}$ with a coolant driving frequency of $60 \mathrm{~Hz}$ and a coolant temperature difference of $2{ }^{\circ} \mathrm{C}$. In comparison with the thermal deformation of the general cooling method (COV/T, a driving frequency of $60 \mathrm{~Hz}$, and a coolant temperature difference of $0{ }^{\circ} \mathrm{C}$ ), the thermal deformation in the $Y$-direction could be reduced to $2.46 \mu \mathrm{m}$.

From the results of the $X$-direction deformation shown in Fig. 6(a), it can be seen that for the spindle with the coolant conditions of variable temperature and variable volume (VOV/T) at a rotating speed of $8000 \mathrm{rpm}$, the deformation of the spindle was not significantly reduced. 
However, the maximum thermal deformation in the $X$-direction was $8.27 \mu \mathrm{m}$ with a coolant driving frequency of $60 \mathrm{~Hz}$ and a coolant temperature difference of $4{ }^{\circ} \mathrm{C}$. Thus, it can be seen that unsuitable cooling conditions or a malfunctioning cooling system will decrease the accuracy of the $X$-direction. From the results of the $Y$-direction deformation, as shown in Fig. 6(b), the thermal deformation in the $Y$-direction with coolant VOV/T control was observed to decrease by $84 \%$ in comparison with that under the general cooling conditions. In Fig. 6(c), it can be seen that the thermal deformation of the spindle was mainly in the $Z$-direction, and its maximum was close to $20 \mu \mathrm{m}$. However, the thermal deformation in the $Z$-direction with the VOV/T method decreased by nearly $13 \%$.

Figure 7(a) illustrates the thermal deformations of the spindle in the $X$-direction at $24000 \mathrm{rpm}$ under different coolant supply conditions. The maximum thermal deformation in the $X$-direction was $-4.1 \mu \mathrm{m}$ with a coolant driving frequency of $40 \mathrm{~Hz}$ and a coolant temperature difference of $4{ }^{\circ} \mathrm{C}$. The minimum thermal deformation in the $X$-direction was $0.66 \mu \mathrm{m}$ with a coolant driving frequency of $60 \mathrm{~Hz}$ and a coolant temperature difference of $2{ }^{\circ} \mathrm{C}$. When the general COV/T method was used under a coolant driving frequency of $60 \mathrm{~Hz}$ and a coolant

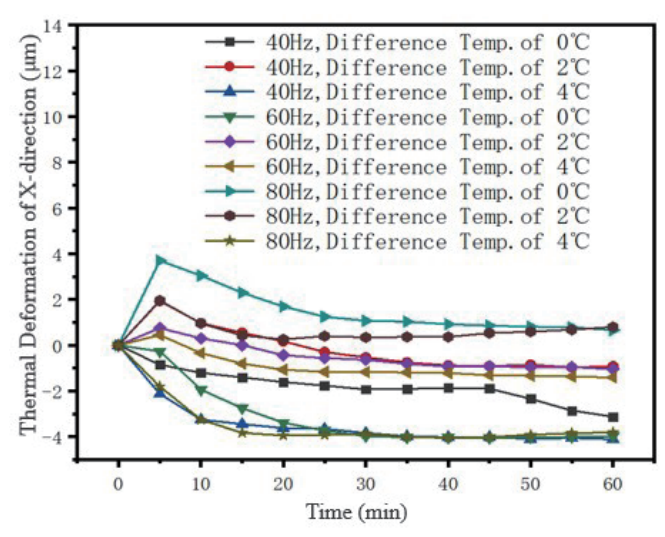

(a)

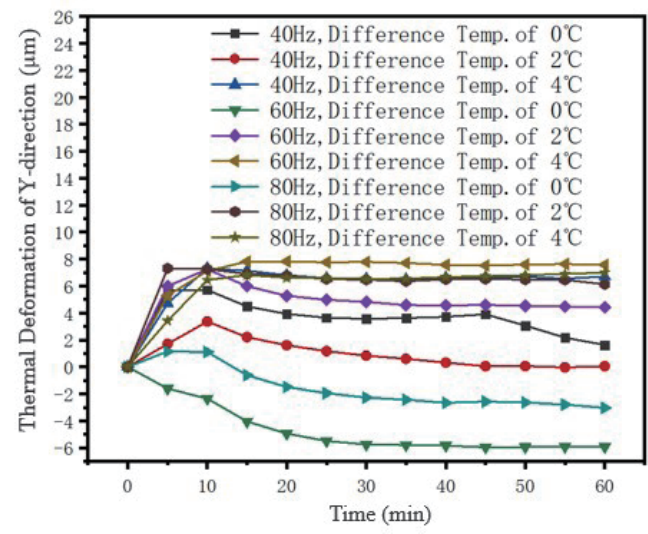

(b)

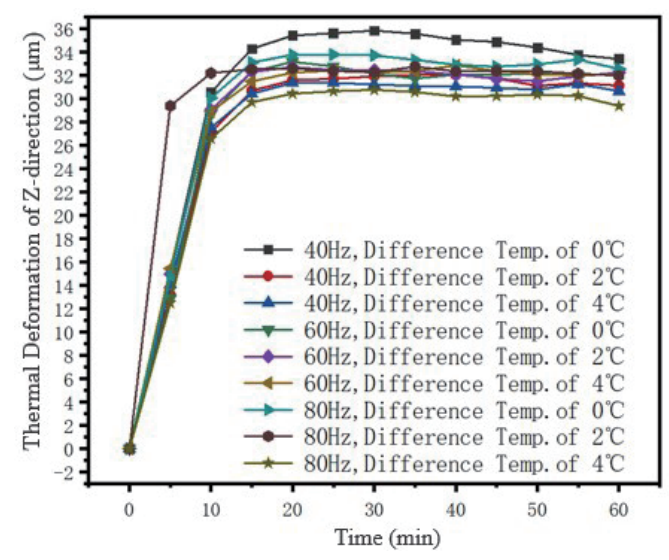

(c)

Fig. 7. (Color online) Thermal deformations of the spindle at $24000 \mathrm{rpm}$ under different cooling oil conditions: (a) $X$-direction, (b) $Y$-direction, and (c) $Z$-direction. 
temperature difference of $0{ }^{\circ} \mathrm{C}$, the thermal deformation was $-3.97 \mu \mathrm{m}$. By comparing the best cooling conditions (a coolant driving frequency of $60 \mathrm{~Hz}$ and a coolant temperature difference of $2{ }^{\circ} \mathrm{C}$ ) with general cooling conditions, the thermal deformation in the $X$-direction was observed to decrease to $3.31 \mu \mathrm{m}$. As shown in Fig. 7(b), the maximum thermal deformation in the $Y$-direction was $7.57 \mu \mathrm{m}$ with a coolant driving frequency of $60 \mathrm{~Hz}$ and a coolant temperature difference of $4{ }^{\circ} \mathrm{C}$. The minimum thermal deformation in the $Y$-direction was 0.05 $\mu \mathrm{m}$ with a coolant driving frequency of $40 \mathrm{~Hz}$ and a coolant temperature difference of $2{ }^{\circ} \mathrm{C}$. With the COV/T method under a coolant driving frequency of $60 \mathrm{~Hz}$ and a coolant temperature difference of $0{ }^{\circ} \mathrm{C}$, the thermal deformation was $-5.93 \mu \mathrm{m}$. As shown in Fig. 7(c), the maximum thermal deformation in the Z-direction was $33.6 \mu \mathrm{m}$ with a coolant driving frequency of $40 \mathrm{~Hz}$ and a coolant temperature difference of $0{ }^{\circ} \mathrm{C}$. The minimum thermal deformation in the $Z$-direction was $29.82 \mu \mathrm{m}$ with a coolant driving frequency of $80 \mathrm{~Hz}$ and a coolant temperature difference of $4{ }^{\circ} \mathrm{C}$. With the COV/T cooling method under a coolant driving frequency of $60 \mathrm{~Hz}$ and a coolant temperature difference of $0{ }^{\circ} \mathrm{C}$, the thermal deformation was $32.08 \mu \mathrm{m}$. By comparing the best cooling conditions (a coolant driving frequency of $80 \mathrm{~Hz}$ and a coolant temperature difference of $4{ }^{\circ} \mathrm{C}$ ) with general cooling conditions, the thermal deformation in the $Z$-direction was observed to decrease to $2.26 \mu \mathrm{m}$. Compared with the general cooling conditions at a spindle speed of $24000 \mathrm{rpm}$, the accuracies of the $X$-, $Y$-, and $Z$-directions increased by $83.4,99.2$, and $7.0 \%$, respectively. The maximum thermal deformation in the $X$-, $Y$-, and Z-directions can be reduced by $3.3,5.9$, and $2.3 \mu \mathrm{m}$, respectively.

Table 1 gives the thermal deformations of the spindle for different cooling oil supply frequencies, temperature differences, and spindle rotating speeds in the experiment. From the table, it can be seen that the thermal deformations in the $X$ - and $Y$-directions were smaller than those in the $Z$-direction at all spindle rotating speeds, and were always less than $10 \mu \mathrm{m}$ and

Table 1

Thermal deformations of spindle for different cooling conditions and spindle rotating speeds.

\begin{tabular}{|c|c|c|c|c|c|c|c|c|c|}
\hline \multirow[b]{2}{*}{$\begin{array}{l}\text { Rotating } \\
\text { speed (rpm) }\end{array}$} & & \multicolumn{2}{|c|}{$X$-direction } & \multicolumn{3}{|c|}{$Y$-direction } & \multicolumn{3}{|c|}{$Z$-direction } \\
\hline & & Deformation & $\begin{array}{l}\text { Cooling } \\
\text { conditions }\end{array}$ & & Deformation & $\begin{array}{c}\text { Cooling } \\
\text { conditions }\end{array}$ & & Deformation & $\begin{array}{l}\text { Cooling } \\
\text { conditions }\end{array}$ \\
\hline \multirow{3}{*}{8000} & Min. & 0.13 & $80 \mathrm{~Hz}, 4{ }^{\circ} \mathrm{C}$ & Min. & 0.42 & $40 \mathrm{~Hz}, 0{ }^{\circ} \mathrm{C}$ & Min. & 16.83 & $60 \mathrm{~Hz}, 2^{\circ} \mathrm{C}$ \\
\hline & Max. & 8.27 & $60 \mathrm{~Hz}, 4{ }^{\circ} \mathrm{C}$ & Max. & 7.77 & $40 \mathrm{~Hz}, 2{ }^{\circ} \mathrm{C}$ & Max. & 19.87 & $40 \mathrm{~Hz}, 4^{\circ} \mathrm{C}$ \\
\hline & $\mathrm{COV} / \mathrm{T}$ & -0.54 & $60 \mathrm{~Hz}, 0{ }^{\circ} \mathrm{C}$ & $\mathrm{COV} / \mathrm{T}$ & -2.7 & $60 \mathrm{~Hz}, 0{ }^{\circ} \mathrm{C}$ & $\mathrm{COV} / \mathrm{T}$ & 19.29 & $60 \mathrm{~Hz}, 0^{\circ} \mathrm{C}$ \\
\hline \multirow{3}{*}{12000} & Min. & 0.35 & $80 \mathrm{~Hz}, 4^{\circ} \mathrm{C}$ & Min. & 0.09 & $60 \mathrm{~Hz}, 2{ }^{\circ} \mathrm{C}$ & Min. & 18.48 & $80 \mathrm{~Hz}, 2^{\circ} \mathrm{C}$ \\
\hline & Max. & -6.42 & $40 \mathrm{~Hz}, 2{ }^{\circ} \mathrm{C}$ & Max. & 8.22 & $80 \mathrm{~Hz}, 4{ }^{\circ} \mathrm{C}$ & Max. & 23.15 & $40 \mathrm{~Hz}, 2^{\circ} \mathrm{C}$ \\
\hline & $\mathrm{COV} / \mathrm{T}$ & -0.99 & $60 \mathrm{~Hz}, 0{ }^{\circ} \mathrm{C}$ & $\mathrm{COV} / \mathrm{T}$ & -2.75 & $60 \mathrm{~Hz}, 0{ }^{\circ} \mathrm{C}$ & $\mathrm{COV} / \mathrm{T}$ & 21.19 & $60 \mathrm{~Hz}, 0^{\circ} \mathrm{C}$ \\
\hline \multirow{3}{*}{16000} & Min. & 0.33 & $80 \mathrm{~Hz}, 0^{\circ} \mathrm{C}$ & Min. & 0.72 & $40 \mathrm{~Hz}, 2{ }^{\circ} \mathrm{C}$ & Min. & 18.85 & $40 \mathrm{~Hz}, 4^{\circ} \mathrm{C}$ \\
\hline & Max. & -5.52 & $60 \mathrm{~Hz}, 4{ }^{\circ} \mathrm{C}$ & Max. & 7.78 & $60 \mathrm{~Hz}, 2{ }^{\circ} \mathrm{C}$ & Max. & 25.05 & $60 \mathrm{~Hz}, 2^{\circ} \mathrm{C}$ \\
\hline & $\mathrm{COV} / \mathrm{T}$ & -5.33 & $60 \mathrm{~Hz}, 0{ }^{\circ} \mathrm{C}$ & $\mathrm{COV} / \mathrm{T}$ & -2.72 & $60 \mathrm{~Hz}, 0{ }^{\circ} \mathrm{C}$ & $\mathrm{COV} / \mathrm{Tt}$ & 22.88 & $60 \mathrm{~Hz}, 0^{\circ} \mathrm{C}$ \\
\hline \multirow{3}{*}{20000} & Min. & 0.13 & $40 \mathrm{~Hz}, 0{ }^{\circ} \mathrm{C}$ & Min. & 0.18 & $60 \mathrm{~Hz}, 4{ }^{\circ} \mathrm{C}$ & Min. & 24.02 & $60 \mathrm{~Hz}, 4^{\circ} \mathrm{C}$ \\
\hline & Max. & 4.82 & $40 \mathrm{~Hz}, 4{ }^{\circ} \mathrm{C}$ & Max. & -3.66 & $60 \mathrm{~Hz}, 0{ }^{\circ} \mathrm{C}$ & Max. & 28.65 & $80 \mathrm{~Hz}, 0^{\circ} \mathrm{C}$ \\
\hline & $\mathrm{COV} / \mathrm{T}$ & 2.91 & $60 \mathrm{~Hz}, 0{ }^{\circ} \mathrm{C}$ & $\mathrm{COV} / \mathrm{T}$ & -3.66 & $60 \mathrm{~Hz}, 0{ }^{\circ} \mathrm{C}$ & $\mathrm{COV} / \mathrm{T}$ & 27.87 & $60 \mathrm{~Hz}, 0^{\circ} \mathrm{C}$ \\
\hline \multirow{3}{*}{24000} & Min. & 0.66 & $60 \mathrm{~Hz}, 2{ }^{\circ} \mathrm{C}$ & Min. & 0.05 & $40 \mathrm{~Hz}, 2^{\circ} \mathrm{C}$ & Min. & 29.82 & $80 \mathrm{~Hz}, 4^{\circ} \mathrm{C}$ \\
\hline & Max. & -4.1 & $40 \mathrm{~Hz}, 4^{\circ} \mathrm{C}$ & Max. & 7.57 & $60 \mathrm{~Hz}, 4^{\circ} \mathrm{C}$ & Max. & 33.6 & $40 \mathrm{~Hz}, 0^{\circ} \mathrm{C}$ \\
\hline & $\mathrm{COV} / \mathrm{T}$ & -3.97 & $60 \mathrm{~Hz}, 0^{\circ} \mathrm{C}$ & $\mathrm{COV} / \mathrm{T}$ & -5.93 & $60 \mathrm{~Hz}, 0^{\circ} \mathrm{C}$ & $\mathrm{COV} / \mathrm{T}$. & 32.08 & $60 \mathrm{~Hz}, 0^{\circ} \mathrm{C}$ \\
\hline
\end{tabular}

Unit of deformation: $\mu \mathrm{m}$ 
almost independent of the spindle rotating speed. However, the thermal deformation in the $Z$-direction gradually increased with the spindle rotating speed from a low value of $16.83 \mu \mathrm{m}$ at $8000 \mathrm{rpm}$ to a high value of $32.08 \mu \mathrm{m}$ at $24000 \mathrm{rpm}$. By adjusting the supply coolant volume and temperature difference according to the spindle rotating speed, the minimum thermal deformations in all direction can be attained.

Table 2 illustrates the reductions in thermal deformation in the $X-, Y$-, and $Z$-directions of the spindle upon adjusting the coolant volume and temperature difference in accordance with the cooling load demand at different spindle speeds. A comparison of the thermal deformation improvements at different spindle rotating speeds by the VOV/T method revealed that the thermal deformation improvements were greater in the $X$ - and $Y$-directions than in the $Z$-direction. The average thermal deformation improvements in the $X$ - and $Y$-directions ranged from 64 to $99 \%$, while those in the $Z$-direction ranged from 7 to $17 \%$.

From the relationship among the spindle rotating speed, coolant volume, and coolant temperature difference in the experiments, the set of cooling conditions for the minimum thermal deformations in all axes is known to vary with the spindle rotating speed. The greatest thermal deformation of the rotating spindle in this study occurred in the $Z$-axis; thus, the set of cooling conditions for the minimum thermal deformation in the $Z$-axis is considered in the following regression analysis. Table 3 shows the cooling conditions for the minimum thermal deformation in the $Z$-axis at different spindle rotating speeds. It can be seen that the driving frequency and coolant temperature difference giving the minimum thermal deformation gradually increased with the spindle rotating speed. In this study, the set of cooling conditions

Table 2

Thermal deformation improvements in the $X$-, $Y$-, and $Z$-directions of spindle at different rotating speeds.

\begin{tabular}{|c|c|c|c|c|c|c|c|c|c|c|c|c|}
\hline \multirow[b]{2}{*}{ RPM } & \multicolumn{4}{|c|}{$X$-direction } & \multicolumn{4}{|c|}{$Y$-direction } & \multicolumn{4}{|c|}{$Z$-direction } \\
\hline & Min. & Max. & $\mathrm{COV} / \mathrm{T}$ & Improvement & Min. & Max. & $\mathrm{COV} / \mathrm{T}$ & Reduction & Min. & Max. & $\mathrm{COV} / \mathrm{T}$ & Improvement \\
\hline 8000 & 0.13 & 8.27 & -0.54 & 75.9 & 0.42 & 7.77 & -2.7 & 84.4 & 16.83 & 19.87 & 19.29 & 12.8 \\
\hline 12000 & 0.35 & -6.42 & -0.99 & 64.6 & 0.09 & 8.22 & -2.75 & 96.7 & 18.48 & 23.15 & 21.19 & 12.8 \\
\hline 16000 & 0.33 & -5.52 & -5.33 & 93.8 & 0.72 & 7.78 & -2.72 & 73.5 & 18.85 & 25.05 & 22.88 & 17.7 \\
\hline 20000 & 0.13 & 4.82 & 2.91 & 95.5 & 0.18 & -3.66 & -3.66 & 95.1 & 24.02 & 28.65 & 27.87 & 13.8 \\
\hline 24000 & 0.66 & -4.1 & -3.97 & 83.4 & 0.05 & 7.57 & -5.93 & 99.2 & 29.82 & 33.6 & 32.08 & 7.0 \\
\hline
\end{tabular}

Unit of deformation: $\mu \mathrm{m}$; Improvement: \%

Table 3

Cooling conditions for minimum thermal deformation in $Z$-axis at different spindle rotating speeds.

\begin{tabular}{ccc}
\hline \multirow{2}{*}{$\begin{array}{l}\text { Rotating speed } \\
\text { of spindle }(\mathrm{rpm})\end{array}$} & \multicolumn{2}{c}{ Cooling conditions } \\
\cline { 2 - 3 } & $\begin{array}{c}\text { Frequency } \\
(\mathrm{Hz})\end{array}$ & $\begin{array}{c}\text { Temperature difference } \\
\left({ }^{\circ} \mathrm{C}\right)\end{array}$ \\
\hline 8000 & 60 & 2 \\
12000 & 80 & 2 \\
16000 & 40 & 4 \\
20000 & 60 & 4 \\
24000 & 80 & 4 \\
\hline
\end{tabular}


for the minimum thermal deformation in the $Z$-axis is subjected to regression analysis to obtain a regression equation to control the cooling of the spindle.

To obtain a multiple regression model from the results listed in Table 3, the driving frequency of the coolant pump was defined as a dependent variable and the rotating speed of the spindle and temperature difference were regarded as independent variables. After the regression analysis of the experimental results shown in Table 3, the final regression model was obtained as

$$
F=0.005 \cdot N-5 \cdot \Delta T^{2}+40
$$

where $F$ is the driving frequency of the coolant pump $(\mathrm{Hz}), N$ is the rotating speed of the spindle (rpm), and $\Delta T$ is the coolant temperature difference $\left({ }^{\circ} \mathrm{C}\right)$.

In the actual machining process, the rotating speed of the spindle is not constant and varies with the machining product, machining mode, and cutting conditions. To validate the feasibility of the developed regression model in actual machining processes, three periods in which the spindle rotating speed was increased to 5,15 , and 30 min were adopted in dynamic experiments. In the experiments, the thermal deformations obtained from the regression model and those for the general cooling conditions $(\mathrm{COV} / \mathrm{T})$ of a constant driving frequency of $60 \mathrm{~Hz}$ and zero coolant temperature difference were compared. Under general actual machining processes $(\mathrm{COV} / \mathrm{T})$, the period during which the rotating speed of the spindle changed was varied from 5 to $30 \mathrm{~min}$. The rotating speed of the spindle was increased from 8000 to $24000 \mathrm{rpm}$ at $4000 \mathrm{rpm}$ increments in periods of 5, 15, and $30 \mathrm{~min}$. Figure 8 illustrates the thermal deformations in the $Z$-axis of the spindle for different operational periods with the increase in spindle rotating speed obtained from the regression model and the general cooling conditions (COV/T, $60 \mathrm{~Hz}$, and a coolant temperature difference of $\left.0{ }^{\circ} \mathrm{C}\right)$.

Figure 8 (a) shows the results obtained when the rotating speed of the spindle was increased beyond $5 \mathrm{~min}$. In comparison with the thermal deformation in the $Z$-axis under the general cooling method, the thermal deformation under the cooling conditions of the regression model was reduced by about $2 \mu \mathrm{m}$ regardless of the spindle rotating speed. Figure 8(b) shows the results obtained when the rotating speed is increased beyond 15 min. Similarly to the results in Fig. 8(a), the thermal deformation in the Z-direction under the cooling conditions of the regression model decreased by $2-3 \mu \mathrm{m}$ at all spindle rotating speeds. By comparing Figs. 8(a) and 8(b), the reduction in thermal deformation under the cooling conditions of the regression equation was found to be greater when the rotating speed was varied in a shorter period. Figure 8(c) shows the results obtained when the rotating speed of the spindle was increased beyond $30 \mathrm{~min}$. The results of the thermal deformation were close to a straight line in the 15 min that presented a stable condition, and the amounts of thermal deformation in the $Z$-direction were the same under the best cooling conditions (see Table 3). However, by comparing the best cooling conditions with the general cooling oil supply method (COV/T, a driving frequency of $60 \mathrm{~Hz}$, and a coolant temperature difference of $0{ }^{\circ} \mathrm{C}$ ), below the spindle rotating speed of $12000 \mathrm{rpm}$, the thermal deformations were consistent, which show that the changes in the coolant flow rate and temperature have no effect on reducing the 


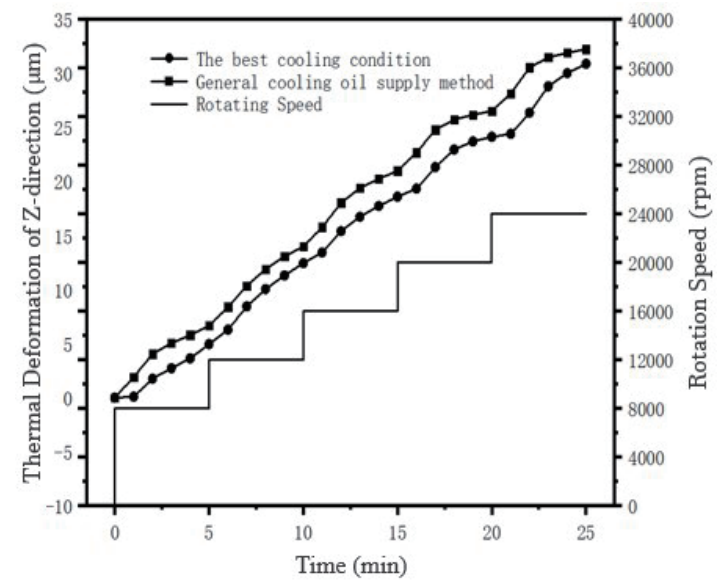

(a)

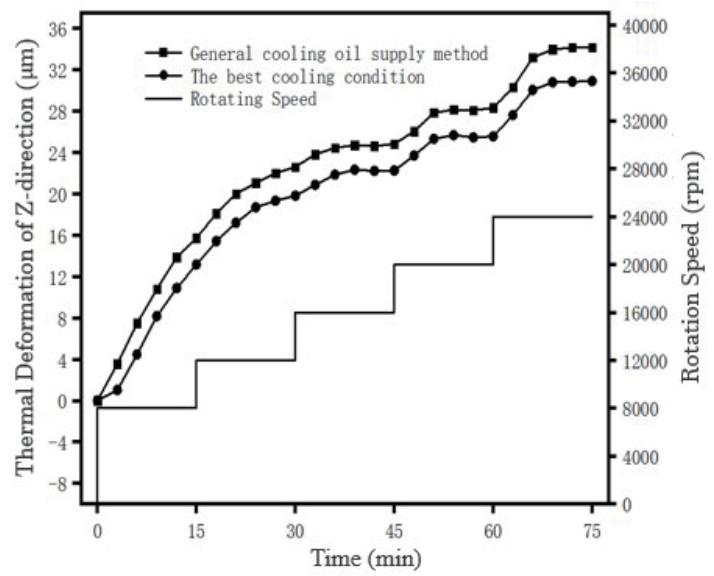

(b)

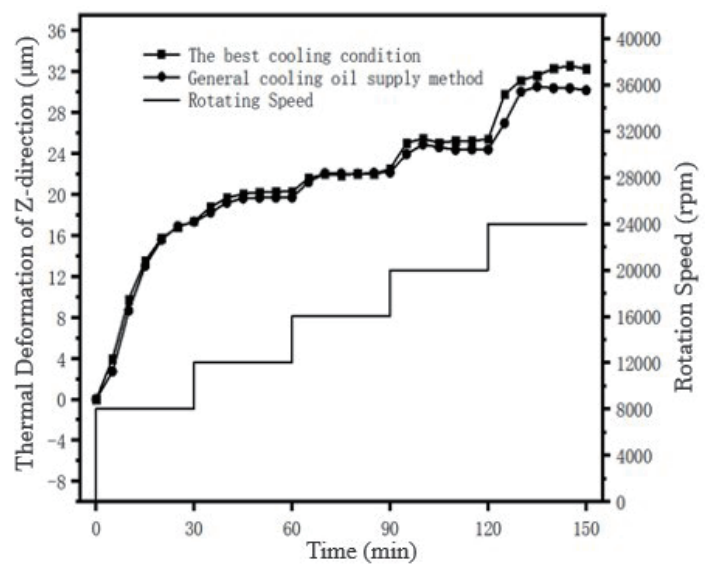

(c)

Fig. 8. Thermal deformations of spindle in $Z$-axis with cooling conditions obtained from regression equation and general cooling method with rotating speed increased in different periods: (a) 5, (b) 15, and (c) 30 min.

thermal deformation of the spindle. In the result of Fig. 8(c), the thermal deformation only slightly differed above $12000 \mathrm{rpm}$. The thermal deformation in the Z-direction under the cooling conditions of the regression model decreased by $3-4 \mu \mathrm{m}$ at a spindle rotating speed of $24000 \mathrm{rpm}$. This result indicates that the VOV/T cooling control method can adapt to the cooling demand of the spindle in rapid dynamic operations.

In a built-in spindle, thermal deformation often occurs as a result of the temperature increase of the front bearing. Therefore, to effectively suppress the generation of thermal deformation, the temperature of the front bearing must be reduced. As shown in Fig. 9, the temperature change of the front bearing varied from 1 to $6{ }^{\circ} \mathrm{C}$ at different speeds when the temperature difference was set to $0{ }^{\circ} \mathrm{C}$. The temperature increase of the front bearing was effectively suppressed at different spindle rotating speeds when the temperature difference was set to $4{ }^{\circ} \mathrm{C}$. The temperature increase of the front bearing was only about $2{ }^{\circ} \mathrm{C}$ at the rotating speeds of 20000 and $24000 \mathrm{rpm}$. 


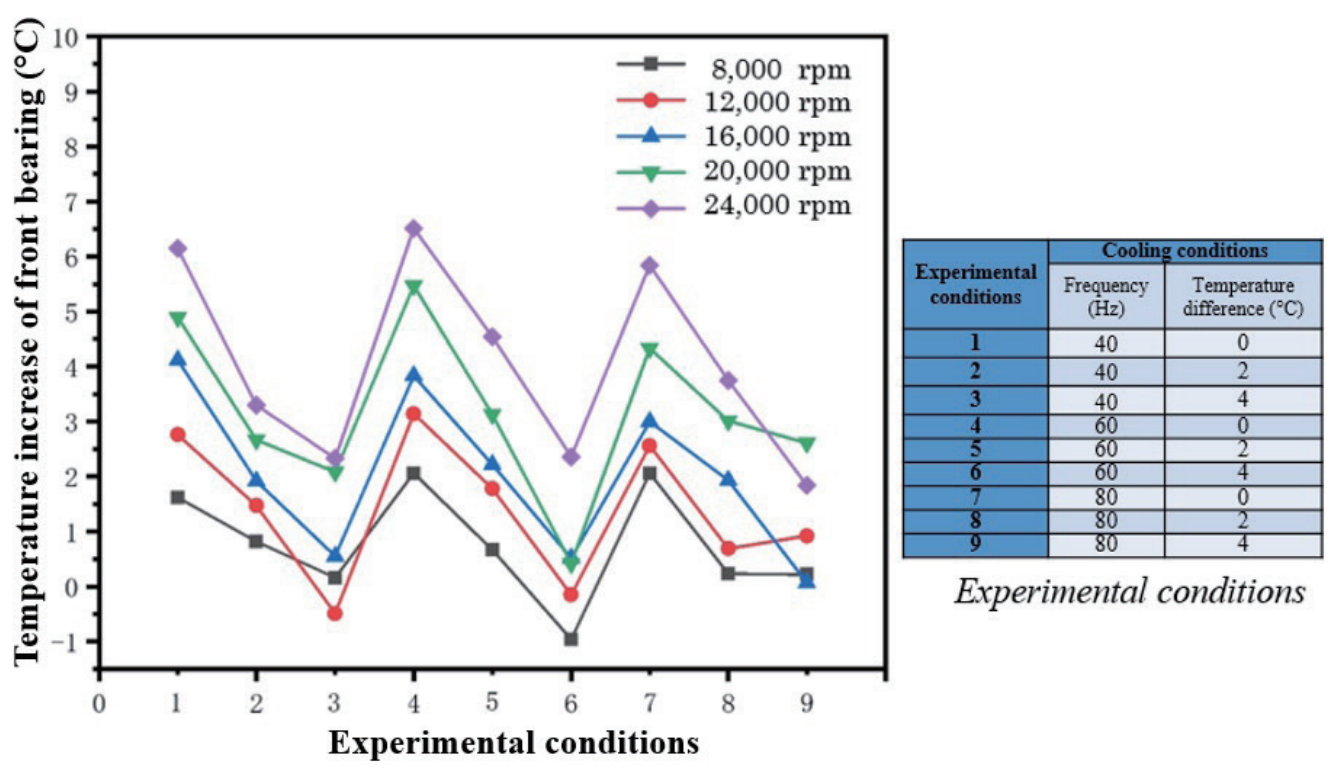

Fig. 9. (Color online) Temperature increases of the front bearing under different spindle rotating speeds.

\section{Conclusions}

The effects of the coolant volume and coolant temperature on the thermal deformation of a spindle were investigated in this study. From the experiments, the thermal accuracy of the spindle was found to be related to the supply coolant volume and coolant supply temperature under different spindle rotating speeds. By adjusting the supply coolant volume and coolant temperature according to the required cooling load demand, the thermal deformation of the spindle could be reduced by $3 \mu \mathrm{m}$ on average under different rotating speeds. Regarding the required power for the spindle, it was observed that when the rotating speed of the spindle was below $17000 \mathrm{rpm}$, the supply voltage increased with the rotating speed. However, when the rotating speed was greater than $17000 \mathrm{rpm}$, the supply voltage was maintained at a value of $367 \mathrm{~V}$. Above a rotating speed of $17000 \mathrm{rpm}$, the supply current dropped significantly. This phenomenon means that the torque of the spindle will gradually decrease above a rotating speed of $17000 \mathrm{rpm}$. The heat generated by the spindle varied with the operational speed. The power consumption of the spindle motor was found to be $118 \mathrm{~W}$ at the operational speed of $8000 \mathrm{rpm}$. As the operational speed of the spindle gradually increased to $24000 \mathrm{rpm}$, the power consumption increased to $369 \mathrm{~W}$. This result indicated that the heat generated inside the spindle increased linearly with the rotating speed of the spindle. By adjusting the supply coolant volume and coolant temperature in accordance with the variation in cooling load, the thermal deformations in the $X$-, $Y$-, and $Z$-directions of the spindle were greatly reduced. The average thermal deformations in the $X$-, $Y$-, and $Z$-directions were reduced by $2.4,3.3$, and $3.1 \mu \mathrm{m}$, respectively. The maximum thermal deformations in the $X$-, $Y$-, and $Z$-directions were reduced by $3.3,5.9$, and $4.0 \mu \mathrm{m}$, respectively. In dynamic experiments, it was found that, under the developed adaptive control model, the thermal deformation of the spindle in the $Z$-direction 
was reduced by $3 \mu \mathrm{m}$ on average in a short period of operation. In particular, the reduction in thermal deformation under the adaptive control model was greater than that occurring in longer periods of operation. Finally, it was found that with a greater coolant supply temperature difference, the temperature increase in the front bearing was also more effectively reduced.

\section{Acknowledgments}

This research was funded by the Industrial Technology Research Institute of Taiwan under Grant No. NCUT15TEP001.

\section{References}

1 K. Y. Li, W. J. Luo, J. Z. Huang, Y. C. Chan, Pratikto, and D. Faridah: Appl. Sci. 7 (2017) 420. https://doi. org/10.3390/app7040420

2 C. Zhang, F. Gao, and Y. Li: Precis. Eng. 47 (2017) 231. https://doi.org/10.1016/j.precisioneng.2016.08.008

3 HIWIN: http://www.hiwin.com.tw/ (accessed September 2020).

4 MIKINO: www.mikino.co.jp (accessed September 2020).

5 H. Shi, B. He, Y. Yue, C. Min, and X. Mei: Appl. Therm. Eng. 161 (2019) 114150. https://doi.org/10.1016/ j.applthermaleng.2019.114150

6 Z. Ge and X. Ding: Appl. Therm. Eng. 125 (2018) 99. https://doi.org/10.1016/j.ijmachtools.2017.11.002

7 DMG-MORI: https://www.dmgmori.co.jp (accessed September 2020).

8 OKUMA: https://www.okuma.co.jp (accessed September 2020).

9 Z. P. Wu, B. Z. Li, J. G. Yang, and R. J. Feng: Appl. Mech. Mater. 44 (2011) 1943. https://doi.org/10.4028/www. scientific.net/AMM.44-47.1943

10 R. S. Moorthy, V. P. Raja, and R. Lakshmipathi: Int. J. Sci. Eng. Res. 3 (2012) 1112. https://www.ijser.org/ viewPaperDetail.aspx?I014873

11 J. Weber, L. Shabi, and J. Weber: Proc. CIRP The 11th CIRP Conf. Intelligent Computation in Manufacturing Engineering (CIRP, 2018) 81-86.

12 K. Y. Li, W. J. Luo, X. H. Hong, S. J. Wei, and P. H. Tsai: IEEE Access 8 (2020) 28988. https://doi.org/10.1109/ ACCESS.2020.2972580

13 K. Y. Li, W. J. Luo, X. H. Hong, S. J. Wei, and P. H. Tsai: 2019 Int. Conf. Smart Science (ICSS2019) 766.

14 J. Vyroubal: Precis. Eng. 36 (2012) 121. https://doi.org/10.1016/j.precisioneng.2011.07.013

15 W. M. Chiang, W. J. Luo, and F. J. Wang: J. Mech. Sci. Technol. 32 (2018) 1391. http://doi: 10.1007/s12206-018$0242-5$

16 K. Y. Li, W. J. Luo, M. H. Yang, X. H. Hong, S. J. Luo, and C. N. Chen: J. Mech. 35 (2019) 887. https://doi. org/10.1017/jmech.2019.29

17 Y. H. Huang, C. W. Huang, Y. D. Chou, C. C. Ho, and M. T. Lee: Smart Sci. 4 (2016) 160. https://doi.org/10.10 80/23080477.2016.1214062

18 S. N. Grama and A. N. Badhe: Int. J. Mach. Tools Manuf. 132 (2018) 3. https://doi.org/10.1016/ j.ijmachtools.2018.04.004

19 K. Mori, B. Bergmann, D. Kono, B. Denkena, and A. Matsubara: CIRP J. Manuf. Sci. Technol. 25 (2019) 14. https://doi.org/10.1016/j.cirpj.2019.04.003

20 Test Code for Machine Tools-Part 3: Determination of Thermal Effects, Standard ISO/FDIS 230-3 (2001).

21 S. J. Kline and F. A. McClintock: Mech. Eng. 75 (1953) 3. https://doi.org/10.1016/0894-1777(88)90043-X

22 HIOKI: https://www.hioki.com/en/ (accessed September 2020).

23 J. M. Gere and S. P. Timoshenko: Mechanics of Materials, J. M. Gere, Ed. (THOMSON, United Kingdom, 2004) 6th ed., Chap. 7.

24 G. Robert Mogull: Second-Semester Applied Statistics, G. Robert Mogull, Ed. (Kendall Hunt Publishing, 2004) p. 59. 


\section{About the Authors}

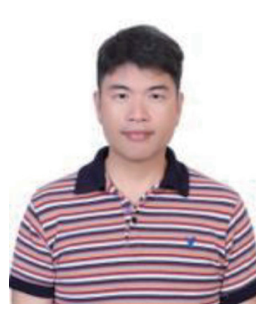

Kun-Ying Li received his B.S. degree from the Department of Bio Mechatronics Engineering, National Chung Hsing University, Taiwan, in 2005 and his M.S. degree from the Department of Mechanical Engineering, National Chung Cheng University, Taiwan, in 2007. He received his Ph.D. degree from the Graduate Institute of Precision Manufacturing, National Chin-Yi University of Technology in 2020. His research interests include thermal errors of machine tools, designs for precision machinery, and reliability engineering and applications. (likunying@ncut.edu.tw)

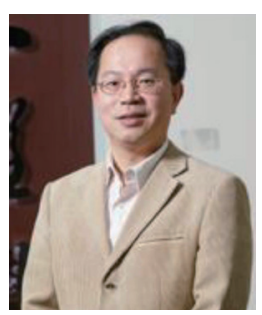

Win-Jet Luo earned his master's degree in engineering in 1994 and his Ph.D. degree in engineering in 2000 from National Chen Kung University (NCKU), Taiwan. At present, he is a professor in the Graduate Institute of Precision Manufacturing, National Chin Yi University of Technology (NCUT). His research has mainly focused on computational fluid dynamics, micro-electromechanical systems, ventilation, energy saving, fuel cells, and microsensors. He has published more than 70 research papers in prestigious international journals and has been invited to serve as a reviewer for journals. (wjluo@ncut.edu.tw)

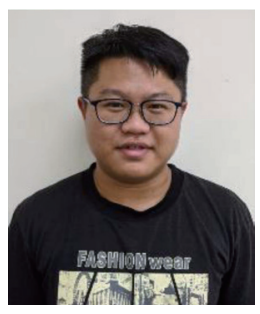

Yu-Ru Zeng received his B.S. degree from the Department of Electrical Engineering, Far East University, Taiwan, in 2018 and his M.S. degree from the Department of Refrigeration, Air-Conditioning and Energy Engineering, NCUT, Taiwan in 2020. (bc9407262@gmail.com)

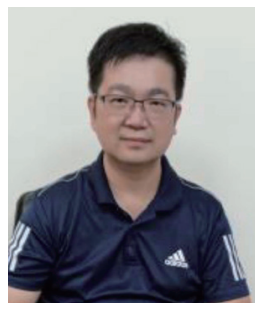

I-Hsing Huang earned his master's and Ph.D. degrees from the Department of Electrical Engineering, NCKU, Taiwan, in 2000 and 2009, respectively. His research interests include single-chip control and embedded system application, energy-saving control of refrigeration and air conditioning, and power electronics. (pestem@ncut.edu.tw) 